\title{
Rare Earths partitioning in a ferruginous/dysoxic geochemical disequilibrium zone
}

\author{
KARELYS UMBRÍA-SALINAS ${ }^{1}$, ASTOLFO VALERO, \\ MSC. $^{2,3}$, JIŘÍ JAN ${ }^{1}$, VLADISLAV CHRASTNÝ ${ }^{4}$ AND \\ DANIEL A PETRASH ${ }^{1,5}$ \\ ${ }^{1}$ Biology Centre CAS \\ ${ }^{2}$ Biology Centre CAS - SoWa \\ ${ }^{3}$ University of South Bohemia \\ ${ }^{4}$ Czech University of Life Sciences \\ ${ }^{5}$ Czech Geological Survey \\ Presenting Author: karelys.umbria@bc.cas.cz
}

Lake Medard, NW Czechia, is a flooded open-cast lignite mine. Its deeper water column now exhibits permanent anoxia. At the ferruginous sediment-water interface (SWI), the sediments contain authigenic Fe(III) mineral phases formed and exported from the redoxcline. Underlying the recent sediments is a weathered claystone containing alteration products formed in an oxic pit-lake. In consequence, discrete Fe-bearing minerals with contrasting crystallinities and redox reactivities (e.g., lepidocrocite, goethite, siderite, and accessory pyrite) occur at variable abundances in the sediment pile to a depth of $16-\mathrm{cm}$. Results from a sequential extraction scheme targeting rare earth elements (REE) bound to reactive iron (FeHR) phases[1] were combined with an assessment of enrichment factors and partitioning coefficients. These parameters were determined by using the concentrations of the lignite and the dissolved [REE] in the anoxic water column and a local acid drainage, respectively. Our analyses show that the $\sum$ REE in the FeHR pool increases from 29 to $91 \mathrm{mg} \mathrm{kg}^{-1}$ towards the bottom of the cores. The partitioning is markedly controlled by the abundance, types, and crystallinities of FeHR phases. LREE appear to be preferentially complexed by poorly crystalline Fe-oxyhydroxides, whilst HREE are relatively more abundant ( 40 to $60 \%$ ) at the sediment depth where siderite $\left(\mathrm{FeCO}_{3}\right)$ increases. Co-evaluation of the concentration of redox-sensitive elements point to remobilization of REE under the current anoxic conditions. Accordingly, reactive minerals formed under oxic conditions in the pit-lake, are leaching their initial REE load across a marked redox interface developed at $\sim 6$-cm depth in the sediments. There, the $\mathrm{Ce}$ anomaly indicates $\mathrm{Ce}(\mathrm{III})$-oxyhydroxides depletion but a concomitant $\mathrm{Ce}$ (IV) enrichment in the carbonate fraction. This is thought to be related to Eh oscillations that affected the partitioning of cerium. With coal powered generation being phased out in Central Europe, reclamation of coal pit mines is expected to lead to the generation of more redox-stratified lakes[2]. As Medard, some of these post-mining lakes might be amenable to secondary metal recovery endeavours that require a sound understanding of the redox dynamics of these systems.

[1] Poulton \& Canfield. Chem. Geo. 214, 209-221. (2005).

[2] Schultze et al. Earth-Sci. Rev. 92, 81-97. 2010. 